\title{
Google Jamboard Sebagai Determinasi Pembelajaran Latsar CPNS Milenial Kabupaten Kampar
}

\author{
Embung Megasari Zam
}

Widyaiswaara Ahli Utama Badan Pengembangan Sumber Daya Manusia Provinsi Riau, Indonesia E-mail: embungmegasari@gmail.com

\begin{abstract}
Abstrak
Peserta Pelatihan Dasar Calon Pegawai Negeri Sipil Daerah Lingkungan Kabupaten Kampar saat ini adalah generasi milenial. Karakteristik milenial sangat melek teknologi, komunikatif, dan multitasking sehingga dibutuhkan pengembangan metode pembelajaran berbasis visual dan menyenangkan, berorientasi pada kreatifitas, dan menerapkan sistem blended learning. Dalam hal ini dengan menggunakan media papan tulis virtual Google Jamboard. Metode pada penelitian ini adalah kuasi-eksperimental hanya pada kelompok yang diteliti. Responden pada penelitian ini adalah peserta Kelas B Pelatihan Dasar Calon Pegawai Negeri Sipil Daerah Angkatan 2 Gelombang I Lingkungan Pemerintah Kabupaten Kampar Provinsi Riau. Teknik pengumpulan data penelitian ini melalui observasi, penyebaran kuesioner, dan dokumentasi. Setelah data terkumpul dianalisis secara kualitatif dengan logiko-induktif yaitu proses berpikir dengan menggunakan logika untuk memahami pola dan kecenderungan dalam data melalui tiga tahap yaitu pengkodean, mendeskripsikan karakteristik utama, dan menginterpretasikan. Hasil penelitian membuktikan bahwa pembelajaran Mata Pelatihan Komitmen Mutu dengan Google Jamboard sudah dapat diterima peserta. Kelebihan pembelajaran ini adalah menarik, kreatif dan inovatif, efektif dan efisien. Kelemahan terbesarnya adalah peserta belum memahami Jamboard karena baru pertama kali menggunakannya. Masukannya, peserta menginginkan untuk diberi pengenalan Jamboard terlebih dahulu. Kelebihan, kelemahan, dan masukan tersebut diharapkan menjadi bahan pertimbangan jika memungkinkan untuk dilakukan evaluasi pasca pelatihan agar mendapat hasil akurat. Terakhir, kelebihan dan manfaat pembelajaran ini menyiratkan ada baiknya pengajar menggunakan Google Jamboard.
\end{abstract}

Kata Kunci: Latsar CPNS, Generasi Milenial, Google Jamboard.

\begin{abstract}
The current participant of the Kampar District Civil Servant Candidates for Basic Training is the millennial generation. Millennial characteristics are very technologically literate, communicative, and multitasking so it requires the development of visual and fun-based learning methods, creativity-oriented, and implementing a blended learning system. In this case using Google Jamboard virtual whiteboard media. The method in this study is quasiexperimental only in the group under study. Respondents in this study were participants of Class E Basic Training for Batch 1 Regional Civil Servant Candidates for Regional Government of Kampar Regency, Riau Province. This research data collection technique through
\end{abstract}


observation, distributing questionnaires, and documentation. After the data collected were analyzed qualitatively with logico-inductive, namely the process of thinking using logic to understand patterns and trends in the data through three stages, namely coding, describing the main characteristics, and interpreting. The results of the study proved that the learning of Quality Commitment Course with Google Jamboard was acceptable to participants. The advantages of this learning are interesting, creative and innovative, effective and efficient. The biggest drawback is that participants don't understand the Jamboard because it's the first time using it. The input, participants want to be given an introduction to the Jamboard first. The strengths, weaknesses, and input are expected to be taken into consideration if it is possible to carry out a post-training evaluation in order to get accurate results. Finally, the advantages and benefits of this learning imply that it is better for teachers to use Google Jamboard.

Keywords: Latsar CPNS, Millennial Generation, Google Jamboard.

\section{Pendahuluan}

Arus globalisasi revolusi industri 4.0 saat ini mendukung kemajuan teknologi informasi, segala aktivitas menjadi tanpa batas dengan perkembangan internet dan teknologi digital (Ristekbrin, 2018). Arus globalisasi revolusi Industri 4.0 erat kaitannya dengan generasi millenial. Bangkitnya generasi milenial menimbulkan tantangan bagi praktik manajemen sumber daya manusia dalam organisasi (Putra, 2016) khususnya pada aktivitas dalam dunia pendidikan dan pelatihan (Nadeak, 2019). Kaitan ini menitikberatkan pola digitalisasi dan otomasi disemua aspek perubahan pada pelaksanaan pendidikan dan pelatihan (Rezky et al., 2019) karena generasi milenial memiliki karakteristik yang sangat melek teknologi digital, komunikatif, dan multitasking, mereka dibesarkan oleh ketersediaan teknologi informasi yang berkembang pesat (Prasasti \& Prakoso, 2020).

Generasi saat ini adalah generasi milenial yaitu generasi yang berumur di bawah 38 tahun karena generasi milenial adalah generasi yang lahir diantara tahun 1981 sampai dengan 2003 (Setiawan \& Puspitasari, 2018). Proporsi Jumlah PNS berstatus aktif di Indonesia tahun 2020 sebanyak 4.121.176 orang. Berdasarkan usia, PNS pada kelompok usia di atas 38 tahun sebanyak 2.911 .266 orang atau $71 \%$, sedangkan PNS di bawah 38 tahun sebanyak 1.229 .910 orang atau hanya $29 \%$ secara keseluruhan (BKN, 2020). Berdasarkan data tersebut dapat disimpulkan mayoritas PNS di Indonesia masih didominasi pada usia 38 tahun ke atas. Namun, komposisi PNS di Indonesia akan terus bertambah tiap tahun nya. Hal ini mengindikasikan bahwa CPNS mulai saat ini dan seterusnya sudah menjadi generasi milenial sehingga metode pendidikan dan pelatihannya juga harus sesuai dengan memanfaatkan kemajuan teknologi informasi dan komunikasi. Pemerintah perlu fokus menyiapkan PNS generasi milenial yang memiliki integritas, etika dan profesional untuk menghadapi tantangan tersebut (BKPP Demak, 2020).

Perkembangan teknologi informasi digital sangat fundamental dan telah membawa perubahan yang signifikan dalam percepatan dan inovasi di bidang pendidikan (Suradji, 2018). Pembelajaran milenial meliputi: model pembelajaran terbimbing berbasis visual dan menyenangkan, berorientasi pada kreatifitas dengan optimalisasi penyediaan media pembelajaran, dan menerapkan sistem blended learning (Daud, 2020). Maka teknologi informasi digital sangat berfungsi untuk membantu memperbarui 
dan mengelola proses pembelajaran dengan optimal (Emalia \& Farida, 2019). Terlebih, mereka adalah generasi yang sangat lekat dengan gawai digital sehingga dapat dimanfaatkan dalam pendidikan dan pelatihan (Wibawanto, 2016). Karena pembelajaran di era digital ini adalah meraka yang berkakter digital native, bersentuhan langsung dengan dunia digital (Afif, 2019). Dibandingkan pembelajaran offline, pembelajaran online saat ini sudah berkembang secara signifikan (Mac Namara \& Murphy, 2017).

Pembelajaran di era milenial sangat bervariasi, Google For Education adalah salah satunya, tidak diragukan lagi karena sudah menjadi situs populer yang banyak digunakan oleh sekitar 70 juta pendidik di seluruh dunia (Maheshwary \& Bhandari, 2019). Situs Google sangat cocok untuk pendidikan dan pelatihan sesuai dengan model pembelajaran 4.0 yang sedang berkembang di Indonesia (Firmansyah et al., 2020). Google For Education menyediakan 8 produk untuk pembelajaran yaitu: Google Workspace for Education, Classroom, Meet, Assignments, Chromebooks, Google Cloud, Virtual \& Augmented Reality dan Jamboard (Google, 2021). Jamboard atau Google Jamboard adalah tempat para guru dan siswa dapat berkolaborasi memberikan ide-ide kreativitas mereka melalui papan tulis virtual, sehingga membuat proses pembelajaran menjadi lebih berinteraktif (Recuero \& Blasco, 2020). Penelitian membuktikan bahwa pembelajaran untuk generasi milenial dengan menggunakan Google Jamboard dapat meningkatkan motivasi belajar dan hasil belajar siswa (Hasanah, 2019).

Kemajuan teknologi informasi yang berbasis pada internet akan mengubah eksistensi dan layanan lembaga diklat dari konvensional menjadi terbarukan (Dahniar, 2019). Dalam pembelajaran bagi generasi milenial, fasilitator perlu memahami tentang keadaan peserta dan tujuan pelatihan, dengan kata lain fasilitator perlu merencanakan pilihan metode dan teknik pembelajaran yang sesuai dengan keadaan dan kegunaan bagi CPNS milenial (Supinah, 2020). Undang-Undang Republik Indonesia Nomor 5 Tahun 2014 Tentang Aparatur Sipil Negara mengatur bahwa Manajemen ASN adalah pengelolaan kompetensi aparatur untuk menghasilkan pegawai profesional, memiliki nilai dasar serta etika profesi pemerintahan. Peran fasilitator dan lembaga kediklatan penting untuk memberikan kontribusi pembelajaran yang nyata sesuai dengan kebutuhan CPNS generasi milenial saat ini sehingga mewujudkan Smart ASN, mengingat kompetensi PNS perlu dikembangkan dan ditingkatkan (Kementerian PANRB, 2017).

Peraturan Lembaga Administrasi Negara Nomor 12 Tahun 2018 Tentang Pelatihan Dasar CPNS menyatakan bahwa latsar CPNS memerlukan desain diklat yang terintegrasi sebagai langkah pembentukan karakter dan kompetensi sesuai tuntutan jabatannya. Selain itu, CPNS saat ini seharusnya mampu menjawab segala tantangan zaman karena sudah menjadi generasi milenial. Penelitian ini akan membuktikan efektifitas terbatas pada penggunaan Google Jamboard sebagai determinasi pembelajaran CPNS generasi milenial untuk meningkatkan pemahaman Mata Pelatihan Komitmen Mutu peserta Pelatihan Dasar CPNS Daerah Angkatan 2 Gelombang I Kelas B di lingkungan pemerintah Kabupaten Kampar Provinsi Riau tahun 2021. Adapun tujuan yang akan dicapai pada tulisan ini yaitu: 1) Untuk mengetahui penggunaan Google Jamboard sebagai determinasi pembelajaran CPNS generasi milenial dalam meningkatkan pemahaman Mata Pelatihan Komitmen Mutu, 2) Untuk mengetahui kekurangan dan kelebihan penggunaan Google Jamboard sebagai determinasi pembelajaran CPNS generasi milenial 
dalam meningkatkan Mata Pelatihan Komitmen Mutu, dan 3) Untuk mengembangkan penggunaan Google Jamboard sebagai determinasi pembelajaran CPNS generasi milenial dalam meningkatkan pemahaman Mata Pelatihan Komitmen Mutu.

\section{Metode}

Metode yang digunakan dalam penelitian ini adalah kuasi-eksperimental hanya pada kelompok yang diteliti (Creswell, 2015) dengan sumber data utamanya adalah kata-kata dan tindakan, selebihnya adalah data tambahan seperti dokumen (Moleong, 2015). Sedangkan yang menjadi instrumen penelitian adalah peneliti itu sendiri (Sugiyono, 2015). Namun untuk mendapatkan data yang relevan guna mempermudah mengumpulkan data juga digunakan instrumen lain berupa lembar kuesioner, catatan observasi, dan dokumentasi.

Penelitian ini dilakukan pada Pelatihan Dasar CPNS Daerah Angkatan 2 Gelombang I Kelas B di Lingkungan Pemerintah Kabupaten Kampar Provinsi Riau yang dilaksanakan pada tanggal 29 30 Maret 2021 di Badan Pengembangan Sumber Daya Manusia (BPSDM) Provinsi Riau ekerja sama dengan Pemerintah Daerah kabupaten Kampar dengan jumlah 40 peserta. Teknik pengumpulan data pada tulisan ini diawali dengan observasi yaitu mengamati respon peserta latsar selama proses pembelajaran berlangsung. Lalu melakukan penyebaran kuesioner terbuka memanfaatkan Google Formulir untuk mengetahui persepsi peserta latsar pasca latsar, kuesioner meliputi poin-poin utama yang menekankan kepada karakteristik responden, kelemahan, kelebihan pembelajaran, dan saran perbaikan kedepan. Serta dokumentasi yang dilakukan adalah mengumpulkan data-data tambahan yang memungkinkan untuk dijadikan relevansi penelitian ini. Data yang terkumpul dianalisis secara logiko-induktif yaitu proses berpikir yang menggunakan logika untuk memahami pola dan kecenderungan dalam data melalui tiga tahap yaitu pengkodean, mendeskripsikan karakteristik utama, dan menginterpretasikan data (Metler, 2019). Interpretasi penelitian ini disajikan dan dibahas secara deskriptif.

\section{Hasil dan Pembahasan}

Proses penerimaan CPNS Daerah di Lingkungan Kabupaten Kampar Provinsi Riau dari tahun ke tahun telah usai, sebagian besar pegawai baru telah bergabung dengan institusi di wilayahnya masing-masing. Namun penerimaan CPNS Daerah di Lingkungan Kabupaten Kampar tidak berhenti sampai disini saja, Perlu disadari bahwa para peserta CPNS Daerah di Lingkungan Kabupaten Kampar pada tahun ini dan tahun berikutnya sudah dan akan menjadi CPNS milenial. Oleh karena itu, CPNS Daerah Lingkungan Kabupaten Kampar identik dengan pribadi yang terbuka, ingin serba cepat, multitasking, memiliki daya kreativitas tinggi, serta ketergantungan tinggi pada teknologi dan informasi pada pembelajaran.

Merujuk pada UU ASN, peserta CPNS Daerah di Lingkungan Kabupaten Kampar sejatinya memiliki urgensi dan peran sebagai penggerak tatakelola pemerintahan, menjadi aparatur profesional, memiliki talenta berkompeten, dan multitasking pada tugas dan fungsinya. Untuk mewujudkan urgensi dan peran tersebut, struktur Kurikulum Pelatihan Dasar CPNS terbagi dalam dua bagian yaitu: 1) Kurikulum Pembentukan Karakter PNS, yang terdiri atas: a) Agenda Sikap Perilaku Bela Negara; b) Agenda Nilai-nilai Dasar PNS; c) Agenda Kedudukan dan Peran PNS dalam NKRI; dan d) Agenda Habituasi; dan 2) Kurikulum Penguatan Kompetensi Teknis Bidang Tugas, yang terdiri atas: a) Agenda untuk memenuhi 
Kompetensi Teknis Administratif; dan b) Agenda untuk memenuhi Kompetensi Teknis Substantif. Di tulisan ini, penelitian terbatas hanya pada pembelajaran Mata Pelatihan Komitmen Mutu.

Mata Pelatihan Komitmen Mutu merupakan pembelajaran Kurikulum Pembentukan Karakter PNS pada Agenda Nilai-nilai Dasar PNS. Mata Pelatihan Komitmen Mutu untuk membekali peserta pelatihan dengan pengetahuan mengenai kemampuan mengaktualisasikan tindakan yang menghargai efektivitas, efesiensi, inovatif, dan kinerja yang berorientasi mutu, dalam penyelenggaraan pemerintahan dan pelayanan publik. Indikator pencapaian keberhasilan dari Mata Pelatihan Komitmen Mutu adalah: 1) menjelaskan tindakan yang menghargai efektivitas, efisiensi, inovasi, dan kinerja berorientasi mutu dalam penyelenggaraan pemerintahan dan pelayanan publik, 2) memberikan contoh sikap perilaku kinerja kreatif dan inovatif yang berorientasi mutu dalam penyelenggaraan pemerintahan dan pelayanan publik, dan 3) menganalisis kasus nilai Komitmen.

Latsar CPNS Daerah Kelas B di Lingkungan Kabupaten Kampar sudah menerapkan blended learning, sebelum pembelajaran tatap muka peserta sudah mempelajari Mata Pelatihan Komitmen Mutu melalui e-learning sehingga saat pembelajaran tatap muka dapat dilakukan pendalaman materi dengan berpedoman pada modul. Untuk dapat mendukung indikator keberhasilan Mata Pelatihan Komitmen Mutu diperlukan sarana pendukung untuk menunjang pembelajaran yang sesuai dengan karakteristik generasi milenial, dalam hal ini yaitu menggunakan media papan tulis virtual Google Jamboard.

Responden pada penelitian ini adalah seluruh Peserta Mata Pelatihan Komitmen Mutu Kelas B Pelatihan Dasar CPNS Daerah Lingkungan Kabupaten Kampar Provinsi
Riau Tahun Pelatihan 2021 dengan jumlah 40 peserta. Berikut dibawah ini peneliti sajikan analisis deskriptif responden dengan kategori jenis kelamin dan umur tiap-tiap peserta.

Tabel 1. Analisis Deskriptif Responden

\begin{tabular}{cccccc} 
No. & Usia & \multicolumn{3}{c}{ Jumlah } & $\%$ \\
& (Tahun) & L & P & L\&P & \\
\hline 1. & $21-25$ & 1 & - & 1 & $3 \%$ \\
2. & $26-30$ & 5 & 16 & 21 & $53 \%$ \\
3. & $31-35$ & 4 & 11 & 15 & $38 \%$ \\
4. & $36-40$ & - & 3 & 3 & $8 \%$ \\
& Total & 10 & 30 & 40 & $100 \%$ \\
\hline
\end{tabular}

Sumber: Data kuesioner yang telah diolah

Berdasarkan analisis data responden pada tabel 1, dapat diketahui bahwa peserta Latsar CPNS Kelas B didominasi dengan jenis kelamin perempuan karena dari 40 peserta, 30 peserta adalah perempuan $(P)$ dan 10 peserta adalah lakilaki (L). Lebih lanjut pada rentang usia, 53\% peserta terbanyak bersia 26-30 tahun dengan jumlah 21 peserta, usia 31-35 tahun berjumlah 15 peserta dengan persentase $38 \%$, usia $36-40$ tahun berjumlah 3 peserta dengan persentase $8 \%$, terakhir $3 \%$ peserta paling sedikit berada pada usia 21-25 tahun dengan jumlah hanya 1 peserta saja.

Selain itu secara spesifik peneliti mengkategorikan kembali apakah peserta peserta Latsar CPNS Kelas B sudah milenial. Berikut dibawah ini tabel kategorisasi peserta berdasarkan rentang umur generasi milenial.

Tabel 2. Kategorisasi Peserta Generasi Milenial

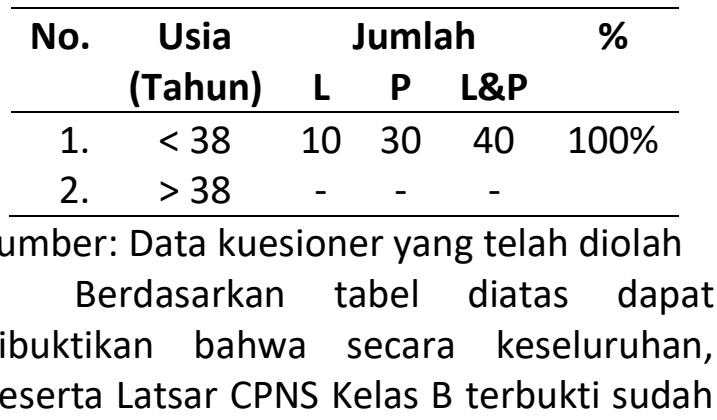


menjadi CPNS milenial. Jumlah CPNS milenial masih didominasi oleh perempuan (P) dengan jumlah 30 peserta, sedangkan sisanya adalah peserta CPNS milenial lakilaki dengan jumlah 10 peserta. Artinya, pembelajaran Mata Pelatihan Komitmen Mutu menggunakan media papan tulis virtual Google Jamboard sudah tepat sasaran dan dapat digunakan pada pembelajaran latsar CPNS Kelas B karena seluruh peserta merupakan generasi milenial. Hal ini sesuai dengan naskah terdahulu yang menyatakan bahwa generasi milenial sangat lekat dengan gawai digital (Wibawanto, 2016). Selain itu terbukti bahwa model pembelajaran sudah terbimbing, berbasis visual dan menyenangkan, serta berorientasi pada kreatifitas dengan optimalisasi penyediaan media pembelajaran dan menerapkan sistem blended learning (Daud, 2020).

Pembelajaran pada Mata Pelatihan Komitmen Mutu bagi peserta Kelas B latsar CPNS milenial Daerah di Lingkup Kabupaten Kampar dengan pemanfaatan media papan tulis virtual Google Jamboard memang baru pertama kali dilakukan pada tahun ini. Keberlangsungan pemanfaatan media pembelajaran ini perlu diketahui melalui minat peserta itu sendiri. Berikut dibawah ini adalah persepsi minat peserta Latsar Kelas B mengenai pembelajaran pada Mata Pelatihan dengan menggunakan media papan tulis virtual Google Jamboard.

Tabel 3. Persepsi Minat Peserta Terhadap Google Jamboard

\begin{tabular}{rlcc}
\hline No. & \multicolumn{1}{c}{ Skala } & Jumlah & $\%$ \\
\hline 1. & Sangat Setuju & 13 & $33 \%$ \\
2. & Setuju & 21 & $53 \%$ \\
3. & Netral & 6 & $15 \%$ \\
4. & Tidak Setuju & - & - \\
5. & Sangat Tidak Setuju & - & - \\
& Total & 40 & $100 \%$ \\
\hline
\end{tabular}

Sumber: Data kuesioner yang telah diolah Berdasarkan tabel 3, skala terbesar yang dijawab oleh peserta mengenai minat terhadap pembelajaran Latsar CPNS dengan pemanfaatan media papan tulis virtual Google Jamboard berada pada skala "setuju" yang dinyatakan oleh 21 responden dengan persentase $53 \%$. Selanjutnya, 13 responden menyatakan "sangat setuju" dengan persentase 33\%. Terakhir, hanya 6 responden dengan persentase $15 \%$ yang menyatakan "Netral". Artinya, secara keseluruhan pembelajaran Latsar CPNS dengan pemanfaatan media papan tulis virtual Google Jamboard sudah diminati dan dapat diterima oleh peserta, karena tidak ada peserta yang menyatakan "tidak setuju" atau "sangat tidak setuju" jika pembelajaran Mata Pelatian Komitmen Mutu ini dilakukan dengan memanfaatkan media papan tulis virtual Google Jamboard. Walaupun ini adalah yang pertama kali menggunakan papan tulis virtual Google Jamboard, minat peserta terhadap penggunaan media pembelajaran tersebut sudah menjawab penelitian terdahulu yang menjelaskan bahwa fasilitator berperan penting memahami keadaan peserta dan tujuan pembelajaran generasi milenial (Supinah, 2020), dengan kata lain fasilitator latsar CPNS Daerah Lingkup Kabupaten Kampar sudah memenuhi kebutuhan pembelajaran peserta dengan memilih metode dan teknik yang terbaik dan tepat sasaran untuk pembelajaran Mata Pelatihan Komitmen Mutu sesuai dengan keadaan dan kegunaannya bagi CPNS generasi milenial.

Setelah pembelajaran selesai peserta Latsar juga diminta pendapatnya dengan pertanyaan apa saja kelebihan pembelajaran Latsar CPNS dengan penggunaan media papan tulis virtual Google Jamboard untuk Mata Pelatihan Komitmen Mutu, jawaban peserta terhadap kelebihan pembelajaran ini dapat dilihat sebagaimana Tabel di bawah ini (jawaban dapat lebih dari satu pada satu responden). 
Tabel 4. Kelebihan Penggunaan Google Jamboard

\begin{tabular}{clcc}
\hline No. & \multicolumn{1}{c}{ Uraian } & Jumlah & $\%$ \\
\hline 1. & $\begin{array}{l}\text { Pembelajaran } \\
\text { Menarik }\end{array}$ & 32 & $63 \%$ \\
2. & $\begin{array}{l}\text { Pembelajaran } \\
\text { Kreatif dan Inovatif }\end{array}$ & 10 & $20 \%$ \\
3. & $\begin{array}{l}\text { Pembelajaran } \\
\text { Efektif dan Efisien } \\
\text { Total }\end{array}$ & 9 & $18 \%$ \\
\hline
\end{tabular}

Sumber: Data kuesioner yang telah diolah

Berdasarkan Tabel 4 diketahui sebesar 63\% dengan jumlah 32 jawaban peserta menyatakan bahwa pembelajaran menggunakan papan tulis virtual Google Jamboard menarik, 10 peserta dengan persentase $20 \%$ menyatakan pembelajaran kreatif dan inovatif, dan 9 peserta dengan persentase $18 \%$ menyatakan bahwa pembelajaran menjadi lebih efektif dan efisien. Oleh karena itu, kelebihan tersebut sudah selaras dengan penelitian terdahulu yang menjelaskan bahwa pembelajaran menarik adalah pembelajaran milenial yang berbasis visual dan menyenangkan (Daud, 2020). Selain itu, pemanfaatan Google Jamboard ini sudah kreatif dan inovatif karena penelitian terdahulu menyatakan dalam rangka optimalisasi pendidikan guna menyongsong era revolusi industri 4.0, inovasi pembelajaran yang dilakukan adalah dengan dibentuknya pembelajaran dengan pemanfaatan teknologi digital (Emalia \& Farida, 2019).

Selain kelebihan, peserta juga diminta pendapatnya terhadap bagaimana kelemahan terhadap pembelajaran Latsar CPNS menggunakan media papan tulis virtual Google Jamboard, uraian nya tersaji pada tabel 5 di bawah ini (jawaban dapat lebih dari satu pada satu responden).

Tabel 5. Kelemahan Penggunaan Google Jamboard

\begin{tabular}{clcc}
\hline No. & Uraian & Jumlah & $\%$ \\
\hline 1. & $\begin{array}{l}\text { Belum Memahami } \\
\text { Google Jamboard }\end{array}$ & 21 & $49 \%$ \\
\hline
\end{tabular}

\begin{tabular}{llc}
\hline 2. $\begin{array}{l}\text { Kendala Jaringan } \\
\text { Internet } \\
\text { 3. }\end{array}$ & 6 & $14 \%$ \\
$\begin{array}{l}\text { Hasil di Board Dapat } \\
\text { Diubah-ubah } \\
\text { Penulisan di Board }\end{array}$ & 5 & $12 \%$ \\
4. & 4 & $9 \%$ \\
5. Terbatas & 4 & $9 \%$ \\
6. $\quad \begin{array}{l}\text { Kurang Efektif dan ada } \\
\text { Efisien } \\
\text { Total }\end{array}$ & 3 & $7 \%$ \\
\hline
\end{tabular}

Sumber: Data kuesioner yang telah diolah Peserta menyatakan bahwa pembelajaran dengan Google Jamboard memiliki 6 kelemahan. $49 \%$ peserta berpendapat bahwa kekurangan terbesar pembelajaran ini adalah mayoritas peserta belum benar-benar memahami Google Jamboard. Artinya karena pembelajaran ini baru pertama kali memanfaatkan Google Jamboard, maka dari itu fasilitator perlu memperhatikan pemahaman peserta, apakah peserta asing atau tidak asing dengan Google Jamboard. Pentignya memberikan review atau tutorial terlebih dahulu sebelum pembelajaran dimulai agar peserta memahami cara penggunaan Google Jamboard. Namun, kelima uraian lainnya juga perlu diperhatikan untuk menjadi identifikasi kelemahan-kelemahan untuk perbaikan dimasa mendatang sehingga dapat mengurangi hambatanhambatan yang terjadi jika memungkinkan untuk selanjutnya akan dilakukan pembelajaran dengan memanfaatkan Google Jamboard secara kontinyu.

Pembelajaran yang baik adalah yang diharapkan dapat mencapai tujuan pembelajaran Latsar CPNS milenial. Untuk mencapai tujuan pembelajaran diperlukan umpan balik dari peserta guna meningkatkan keberhasilan, memperbaiki kesalahan, membantu untuk mengungkapkan kesalah pahaman, dan memberi saran perbaikan untuk pembelajaran yang akan datang. Umpan balik disesuaikan dengan kehendak peserta. Oleh karena itu peserta diminta 
untuk memberikan pendapatnya dengan pertanyaan apa masukan Anda agar pembelajaran mata pelatihan Komitmen Mutu menggunakan papan tulis virtual Google Jamboard menjadi lebih efektif dan efisien, jawabannya sebagaimana Tabel 5 .

Tabel 5. Masukan Peserta Terhadap Penggunaan Google Jamboard

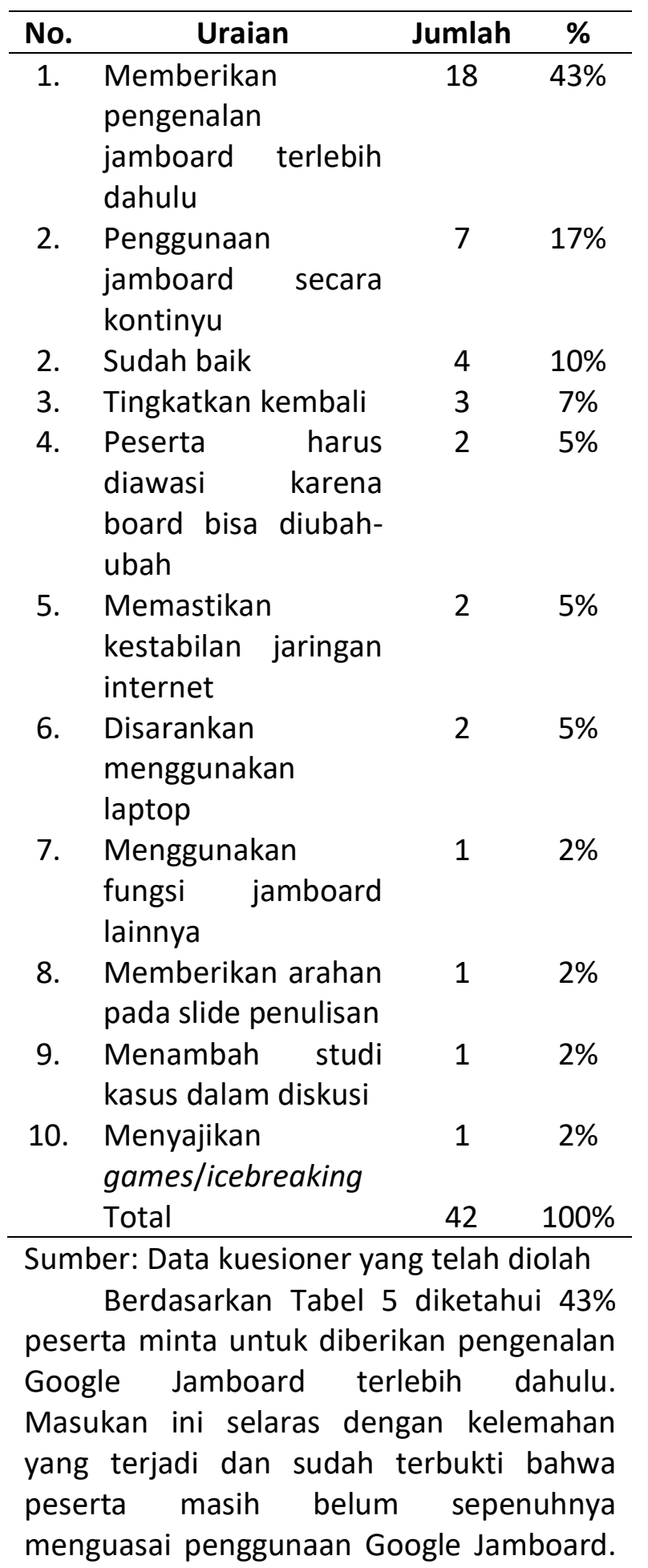

Walaupun peserta CPNS sudah milenial, mahir dalam menggunakan gawai digital, tetapi ketika mereka dihadapi dengan media pembelajaran yang baru tanpa ada pengenalan terlebih dahulu peserta akan mengalami kesulitan untuk memahami pembelajaran. Masukan ini harus mendapat perhatian karena meskipun pembelajaran sudah menarik, jika peserta tidak sepenuhnya mengerti dan memahami fungsi kegunaan Google Jamboard, pembelajaran akan menghabiskan waktu karna peserta hanya akan kebingungan menggunakan Jamboard sehingga materi yang disampaikan menjadi tidak tuntas. Dengan ini fasilitator memungkinkan untuk memberikan pemahaman sebelum pembelajaran dilakukan seperti memberikan video tutorial atau hanya sebatas tata cara penggunaan Jamboard.

Masukan mengenai penggunaan Jamboard secara kontinyu memberi arti bahwa $17 \%$ peserta menginginkan untuk selanjutnya Jamboard ini tetap digunakan untuk pembelajaran Latsar, peserta ingin Jamboard lebih sering digunakan pada setiap pemberian materi dan tugas dan membuat lebih banyak diskusi untuk saling berbagi ide-ide kreatif. Selain itu 10\% peserta menyatakan bahwa penggunaan Google Jamboard sudah baik. 7\% peserta menyatakan perlu ditingkatkan kembali mengingat penggunaan Jamboard ini baru pertama kali dan juga masih terdapat kelemahan yang terjadi.

Dikarenakan hasil jawaban di Jamboard bisa diedit dan diubah-ubah sewaktu waktu sesuai kemauan, dalam hal ini peserta perlu diawasi agar tidak iseng dalam mengubah jawabannya. Uraian saran lainnya juga perlu dipertimbangkan walaupun secara keseluruhan pembelajaran dengan media papan virtual Jamboard ini sudah dapat diterima kelayakan nya, namun saran peserta memungkinkan untuk menjadi rekomendasi yang konstruktif. Pada 
akhirnya, pembelajaran latsar CPNS milenial menggunakan media papan tulis virtual Jamboard ini akan menyajikan halhal apa saja yang dapat dipertahankan, harus dilakukan perbaikan, ataupun perlu untuk ditingkatkan kembali.

\section{Simpulan}

Sebanyak 40 peserta Latsar CPNS Kelas B Daerah Lingkungan Kabupaten Kampar merupakan generasi milenial. Pembelajaran Mata Pelatihan Komitmen Mutu pada Latsar CPNS milenial ini menanfaatkan media papan tulis virtual Google Jamboard. Karena baru pertama kali menggunakan, penggunaannya sudah dapat diterima peserta karena tidak ada yang menyatakan tidak setuju. Kelebihan pembelajaran ini adalah menarik, kreatif dan inovatif, efektif dan efisien. Kelemahan terbesarnya adalah peserta belum memahami Jamboard karena fasilitator tidak memfasilitasi pengenalan fungsi dan kegunaan Jamboard sebelumnya. Sebagai masukan, peserta menyatakan agar diberikan sosialisasi pengenalan Jamboard terlebih dahulu sebelum pelatihan dilaksanakan seperti pemberian tutorial berbentuk dokumen atau video.

Latsar CPNS Daerah Lingkungan Kabupaten Kampar sudah milenial, metode pembelajaran dengan pemanfaatan Google Jamboard sudah menyesuaikan karakteristik mereka. Kelebihan, kelemahan, dan masukan pada temuan penelitian ini diharapkan menjadi bahan pertimbangan di masa mendatang, jika memungkinkan perlu dilakukan evaluasi pasca pelatihan agar hasil lebih akurat. Selebihnya, pembaharuan pembelajaran ini memiliki kelebihan dan manfaat sehingga ada baiknya pengajar menggunakannya.

\section{Daftar Pustaka}

Afif, N. (2019). Pengajaran dan Pembelajaran di Era Digital. IQ (IImu Al-Qur'an): Jurnal Pendidikan Islam, 2(1),

117-129. https://doi.org/10.37542/iq.v2i01.28

BKN. (2020). Buku Statistik Pegawai Negeri

Sipil Juni 2020. Badan Kepegawaian Negara.

BKPP Demak. (2020). Dibutuhkan ASN Milenial Yang Berintegritas. Berita. https://bkpp.demakkab.go.id/2020/0 7/dibutuhkan-asn-milenial-yang.html Dibutuhkan

Creswell, J. (2015). Riset Pendidikan, Perencanaan, Pelaksanaan, dan Evaluasi Riset Kualitatif \& Kuantitatif (5th ed.). Pustaka Pelajar.

Dahniar, A. (2019). Layanan Diklat Di Era Millenial. Tatar Pasundan: Jurnal Diklat Keagamaan, 13(1), 36-49. https://doi.org/10.38075/tp.v13i1.11

Daud, A. (2020). Strategi Guru Mengajar Di Era Milenial. Al-Mutharahah: Jurnal Penelitian Dan Kajian Sosial Keagamaan, 17(1), 29-42. https://doi.org/10.46781/almutharahah.v17i1.72

Emalia, E., \& Farida, F. (2019). Inovasi Pendidikan Dengan Memanfaatkan Teknologi Digital Dalam Upaya Menyonsong Era Revolusi Industri 4.0. Prosiding Seminar Nasional Pendidikan Program Pascasarjana Universitas Pgri Palembang, 160-169. https://jurnal.univpgri-

palembang.ac.id/index.php/Prosiding pps/article/view/2984/0

Firmansyah, F. H., Sari, I. P., Permana, F. C., \& Hernawan, A. H. (2020). Development of Interactive Learning Media Based on Google Application for Distance Learning in Universitas Pendidikan Indonesia. Advances in Social Science, Education and Humanities Research, International Conference on Educational Research and Innovation (ICERI 2019), 401, 185-190.

https://doi.org/10.2991/assehr.k.200 204.034

Google. (2021). Google For Education: 
Komitmen

Kami.

https://edu.google.com/intl/id_ALL/w

hy-google/our-commitment/

Hasanah, E. (2019). Pengaruh Media Jamboard Terhadap Motivasi Belajar Dan Hasil Belajar Tajwid (Studi Asosiasi pada Siswa Kelas IX SMP Islam Al Azhar 1 Jakarta) TESIS. Institut IImu Al-Quran Jakarta.

Kementerian PANRB. (2017). Kiprah Kementerian PAN-RB: Reformasi Birokrasi. Biro Hukum Komunikasi dan Informasi Publik Kementrian PANRB.

Mac Namara, D., \& Murphy, L. (2017). Online Versus Offline Perspectives On Gamified Learning. CEUR Workshop Proceedings, 1857, 47-52.

Maheshwary, P., \& Bhandari, A. (2019). Case Study Google For Education. International Conference on Digital Pedagogies, 1-11. http://ssrn.com/link/2019-Int-ConfICDP.html

Metler, C. A. (2019). Action Research: Improving Schools and Empowering Educators (6th Ed.). SAGE Publications.

Moleong, L. J. (2015). Metodologi Penelitian Kualitatif. Remaja Rosdakarya.

Nadeak, B. (2019). Bahan Ajar Manajemen Sumber Daya Manusia Pendidikan Era Industri 4.0 (1st ed.). Unit Penerbitan dan Publikasi Universitas Kristen Indonesia.

https://doi.org/10.31219/osf.io/yq85t

Prasasti, S., \& Prakoso, E. T. (2020). Karakter Dan Perilaku Milenial: Peluang Atau Ancaman Bonus Demografi. Jurnal Consilia, 3(1), 10 23.

Putra, Y. S. (2016). Theoritical Review: Teori Perbedaan Generasi. Among Makarti, 9(18), 123-134.

Recuero, N., \& Blasco, M. (2020). Google Jamboard Interactive Smart board: Are Innovative Approaches Useful in
Personal Branding Assignments? 2nd World Conference on Future of Education, 2, 1-6.

Rezky, M. P., Sutarto, J., Prihatin, T., Yulianto, A., \& Haidar, I. (2019). Generasi Milenial yang Siap Menghadapi Era Revolusi Digital (Society 5.0 dan Revolusi Industri 4.0) di Bidang Pendidikan Melalui Pengembangan Sumber Daya Manusia. Prosiding Seminar Nasional Pascasarjana (PROSNAMPAS), 2(1), 1117-1125.

https://proceeding.unnes.ac.id/index. php/snpasca/article/view/424

Ristekbrin. (2018). Pengembangan Iptek dan Pendidikan Tinggi di Era Revolusi Industri 4.0. Rakernas Kemenristekdikti.

https://www.ristekbrin.go.id/pengem bangan-iptek-dan-pendidikan-tinggidi-era-revolusi-industri-4-0-2/

Setiawan, S. A., \& Puspitasari, N. (2018). Preferensi Struktur Organisasi Bagi Generasi Millenial. Jurnal Borneo Administrator, 14(2), 101-118. https://doi.org/10.24258/jba.v14i2.33 6

Sugiyono. (2015). Metode Penelitian Pendidikan. Alfabeta.

Supinah. (2020). Fasilitator Keren Dengan Pilihan Metode Dan Teknik Pembelajaran Pada Pelatihan Bagi Generasi Milenial. Jurnal Kkewidyaiswaraan, 5(2), 26-38.

Suradji, M. (2018). Pengembangan Teknologi Informasi Dan Komunikasi Bidang Kesiswaan, Kepegawaian Dan Keuangan Di SMA Muhammadiyah 1 Gresik. TA'LIM: Jurnal Studi Pendidikan Islam, 1(2). https://core.ac.uk/download/pdf/229 347961.pdf

Wibawanto, H. (2016). Generasi Z dan Pembelajaran di Pendidikan Tinggi. Simposium Nasional: Mengenal Dan Memahami Generasi Z. Haruskah 
Pendidikan Tinggi Berubah?, 1-10.

\section{Profil Penulis}

Ir. Embung Megasari Zam M.Si., Widyaiswara BPSDM Provinsi Riau. Dilahirkan di Tanjung Batu, Kepulauan Riau pada tanggal 18 Desember 1960. Menempuh pendidikan terakhir pascasarjana magister program studi Admininistrasi Publik dan lulus pada tahun 2016. Mengawali karir sebagai CPNS golongan II/b tahun 1986 di Kecamatan Air Tiris, Kabupaten Kampar, Provinsi Riau.

Mulai tahun 2010 melepaskan jabatan struktural saat itu (esselon 3), memilih menjadi fungsional Widyaiswara. Tahun 2011-2018 sudah mengampu dan menjadi fasilitator pada mata pelatihan Budaya Kerja, Pelayanan Prima, Kecerdasan Emosional, Outbound, Dinamika Kelompok, Etika dalam Organisasi, Pengembangan dan Pengenalan Potensi Diri, Komunikasi Efektif, Koordinasi dan Kolaborasi, Membangun Tim Efektif, Jejaring Kerja dan Kepemimpinan dalam Organisasi. Tahun 2019 menjadi Team Teaching pada Agenda II PKA dan PP, serta pada pelaksanaan Pelatihan Dasar CPNS mengampu materi Komitmen Mutu dan Pelayanan Publik. Selain itu juga diberi kepercayaan sebagai Coach. Aktif di beberapa organisasi antara lain Lembaga Adat Melayu Riau, APWI, ATrl, dan pernah menjadi Ketua IWI Daerah Riau periode tahun 2014-2017. Kemudian terhitung November 2019 dikukuhkan sebagai Widyaiswara Ahli Utama oleh Kepala Lembaga Administrasi Negara. 